\title{
A ARTE COMO ARTE DE EXISTÊNCIA: EXPERIÊNCIAS DE SOCIALIZAÇÃO DE JOVENS DE ORIGEM POPULAR EM SALVADOR, BAHIA
}

\author{
THE ART AS ART OF EXISTENCE: EXPERIENCES OF SOCIALIZATION OF YOUNG PEOPLE OF ORIGIN POPULAR IN \\ SALVADOR, BAHIA
}

EL ARTE COMO ARTE DE LA EXISTENCIA: EXPERIENCIAS DE SOCIALIZACIÓN DE JÓVENES DE ORIGEN POPULAR EN SALVADOR, BAHIA

\author{
FARIA, Ivan 1 \\ FERREIRA, Vitor Sérgio ${ }^{2}$ \\ DAYREL, Juarez Tarcísio ${ }^{3}$
}

\begin{abstract}
RESUMO
Neste artigo analisamos experiências de socialização artística de jovens de origem popular, que investiram na formação e profissionalização no mundo das artes. Discutimos os papéis socializadores do bairro, da igreja, das mídias e de projetos socioculturais para a formação do artista. O trabalho fundamenta-se na literatura sociológica sobre juventude, socialização e profissões artísticas. A análise centra-se nas experiências de nove jovens que realizaram formação profissionalizante e se tornaram profissionais em música, dança, vídeo e fotografia, em Salvador, Bahia. Os resultados apontam a importância de novos contextos socializadores para a construção de mundos artísticos menos elitizados e abertos. Os participantes da pesquisa mostram que mesmo diante de horizontes incertos para a juventude, não deixam de desejar e trabalhar para converter sonhos em projetos profissionais ou em artes de subsistência.
\end{abstract}

Palavras-chave:Juventude. Mundo artístico. Socializaçãoartística.

\section{ABSTRACT}

In this article we analyze experiences of artistic socialization of young people from working classes, who invested in training and professionalization in the arts world. We discuss the socializing roles of the neighborhood, the church, the media, and sociocultural projects for the artist's training. The work is based in the sociological literature on youth, socialization and artistic professions. The analysis focuses on the experiences of nine young people who have completed vocational training and become workers in Music, Dance, Video and Photography, in Salvador, Bahia. The results point to the importance of new socializing contexts to construct art worlds, less elitist and open. Participants in the research show that even in the face of uncertain horizons for youth, they still want and work to convert dreams into professional projects or subsistence arts.

Keywords: Youth. Artistic world. Artistic socialization. Arts of existence.

\section{RESUMEN}

En este artículo analizamos experiencias de socialización artística de jóvenes de origen popular, que invirtieron en la formación y profesionalización en el mundo de las artes. Discutimos los papeles socializadores del barrio, de la iglesia, de los medios y de proyectos socioculturales para la formación del artista. El trabajo se fundamenta en la literatura sociológica sobre juventud, socialización y profesiones artísticas. El análisis se centra en las experiencias de nueve jóvenes que realizaron formación profesional y se tornaron profesionales en música, danza, vídeo y fotografía, en Salvador, Bahía. Los resultados apuntan a la importancia de nuevos contextos socializadores para la construcción de mundo de las artisticos menos elitizados y abiertos. Los participantes de la investigación muestran que incluso ante horizontes inciertos para la juventud, no dejan de desear y trabajar para convertir sueños en proyectos profesionales o en artes de subsistencia.

Palabras clave:Juventud. Mundo artístico. Socialización artística. Artes de la existência.

\footnotetext{
1 Universidade Estadual Feira de Santana- UEFS - Feira de Santana - Bahia - Brasil .

2 Instituto de Ciências sociais da Universidade de Lisboa - ICS - Lisboa - Portugal.

3 Universidade Federal de Minas Gerais - UFMG - Belo Horizonte - Minas Gerais - Brasil.
} 


\section{INTRODUÇÃO}

Nos últimos anos, houve um expressivo desenvolvimento do setor cultural no Brasil e no mundo, em termos de participação na economia, implantação de políticas públicas e possibilidades de formação (INFOCULTURA, 2014; LAWRENCE; PHILLIPS, 2009). Esse cenário tem contribuído também para uma abertura dos mundos das artes tradicionais e consagradas e para a intensificação de processos de artificação de setores que até recentemente não eram vistos como artísticos (SHAPIRO; HEINICH, 2013). ${ }^{4}$ A amplificação e a porosidade das fronteiras dos setores artísticos têm convergido para uma democratização relativa do acesso aos mundos das artes, tanto em termos de fruição/consumo, como da produção do "ser artista" (ALMEIDA, 2012; FERREIRA, 2010, 2017), com a ampliação das possibilidades de pessoas oriundas de classes populares participarem de processos de socialização e de inserção social nesse campo.

No que se refere aos processos de formação de um artista, ainda persistem mitos e idealizações, que sugerem que as habilidades artísticas seriam reservadas a alguns poucos indivíduos privilegiados dotados de "talento", "vocação" ou "dom". No entanto, desde que a sociologia se dedicou às artes, com trabalhos como As Regras da Arte, de Bourdieu (1996), ou Os Mundos das Artes, de Howard Becker (1977), que sobressaem os mecanismos de reprodução na família e na escola formal, destacadamente as instituições especializadas às quais só tinham acesso os culturalmente privilegiados, colocando em questão o peso "natural" das habilidades artísticas.

Se pensarmos a socialização artística como um longo processo de construção de habilidades, sensibilidades e significados em torno das artes, há que se considerar também o papel formativo das inúmeras experiências de contato com as artes desenvolvidas em espaços não formais do bairro, da igreja, das mídias ou de um projeto social.

Entre jovens brasileiros de classes populares, os processos de alargamento dos mundos artísticos e de artificação de práticas e materiais têm também ampliado os modos de fruir, aprender e fazer arte, institucionalizando outros contextos de mediação/socialização.

Neste artigo pretendemos abordar experiências de socialização artística de jovens de origem popular, que não apenas se interessaram ou se envolveram ludicamente com artes no cotidiano, mas que também fizeram dessa relação com o mundo artístico um espaço de realização de desejos e de profissionalização. ${ }^{5}$

\footnotetext{
${ }^{4}$ A noção de artificação (SHAPIRO; HEINICH, 2013) se refere a processos de transformação de objetos, pessoas, representações, que antes não eram tratados como arte - ou artísticos - e que passam a sê-lo. Se no passado, pintores e artesãos viveram tal processo ao adquirirem status de artistas, contemporaneamente o vivem os que trabalham com o grafite, o vídeo, o design gráfico, a moda ou profissionais como DJs, tatuadores etc. (FERREIRA, 2017; FERREIRA; RAIMUNDO, 2014).

${ }^{5}$ Assim como Ferreira (2017), adotamos a noção de profissionalização como um "[...] processo subjetivo de pensar e investir numa determinada atividade social como possível meio de vida, reconhecendo-lhe potencial de empregabilidade e aspirando a dela obter rendimentos para subsistir" (FERREIRA, 2017, p. 477), diferindo do seu uso nas sociologias das profissões, que a entendem como um processo de legitimação, reconhecimento e regulação de determinadas ocupações.
} 
São jovens que nasceram em um contexto de novas relações com o trabalho - mais flexíveis, incertas e dinâmicas - e que têm sido socializados em contextos profissionais menos normatizados e rígidos. Eles incorporam valores como o presentismo, o hedonismo e o experimentalismo (FERREIRA, 2016), e têm conseguido

[...] obter, na sua actividade profissional, uma peculiar fusão entre identidade e trabalho, entre o projecto de vida que construíram a partir da esfera do lazer e do consumo e o meio de vida necessário para sua manutenção, mantendo-se em cena a tempo inteiro. (FERREIRA, 2010, p. 117).

Em outras palavras, falamos de jovens que têm convertido suas relações com o mundo artístico menos em um espaço de resistência, como presente nas (sub)culturas juvenis dos anos 1970 e 1980, e mais em "artes de existência", como pontua Ferreira $(2010,2016)$, inspirado em Foucault, no sentido de uma busca por ser diferente, autêntico e soberano de si.

A análise centra-se na experiência de nove jovens de Salvador, nascidos em bairros populares e que se tornaram profissionais nas áreas das artes e da cultura. Estes sujeitos participaram de um estudo mais abrangente (FARIA, 2017), realizado entre os anos de 2013 e 2017, que envolveu 209 egressos de cursos técnicos em dança e música, ofertados por duas escolas públicas estaduais, e de um projeto educativo em vídeo e fotografia, promovido por uma Organização Não Governamental.

O material empírico foi obtido por meio de entrevistas em profundidade com jovens, que são caracterizados brevemente, a seguir, por nomes fictícios, seguidos da idade e da abreviatura da área de formação e uma pequena descrição dos seus perfis sociais e profissionais.

Os egressos são: Sidinei (29, DAN), filho de um pescador e de uma empregada doméstica, possui formação técnica e superior em dança e atua como dançarino, coreógrafo, educador e produtor artístico e cultural; lara (27, DAN), cuja mãe é pensionista e o pai era eletrotécnico, técnica em dança e bacharela em Artes e atua como dançarina e produtora cultural; Lia (26, DAN), filha de um eletricista e de uma professora, técnica em dança e graduada em Psicologia e trabalha como dançarina; Ismael (30, MUS), cujo um pai é feirante e a mãe ex-auxiliar de cozinha, técnico em regência e licenciado em música e atua como educador musical, músico de eventos, instrumentista e cantor; Diego (29, MUS), filho de um corretor de imóveis e de uma dona de casa, técnico em instrumento musical e licenciado em música, baixista e educador musical; Murilo (27, VID), cuja mãe é dona de casa e o pai técnico em manutenção, tem formação de nível médio em vídeo e bacharelado em artes, é cinegrafista, fotógrafo, editor, produtor e videomaker, Maria (27, VID), que tem um pai pedreiro e uma mãe empregada doméstica, tem formação profissionalizante em vídeo e cursa o bacharelado em artes, atua como arteeducadora, videomaker e produtora cultural; Carina (26, FOT), cuja mãe era dona de casa e o pai é vigilante, tem formação profissionalizante em fotografia e bacharelado em artes, é arte-educadora e fotógrafa; e Larissa (23, FOT), filha de um motorista e de uma dona de casa, é formada em fotografia, 
possui duas graduações tecnológicas (produção audiovisual e design de interiores) e atua como fotógrafa.

A seguir, são analisadas algumas dimensões constitutivas dos processos de socialização artística no bairro, na igreja e nas mídias, enquanto contextos de familiarização precoce com as artes e em projetos sociais, como espaços de formação e "pré-profissionalização".

\section{SOCIALIZAÇÕES COTIDIANAS: O BAIRRO, AS MÍDIAS E A IGREJA}

Habilidades artísticas que são vistas como fruto de algum "dom", muitas vezes são precocemente construídas e naturalizadas a partir de relações com objetos e práticas artísticas em contextos familiares, escolares ou cotidianos (BOURDIEU, 1996).

Se, por um lado, socialização em dança e música muitas vezes inicia-se precocemente, em outras áreas, como o vídeo e a fotografia, cujas práticas raramente estão presentes no cotidiano de jovens de origem popular, a percepção sobre a existência de habilidades específicas inatas para tais linguagens artísticas tende a ser mais relativizada.

Num ambiente familiar, um indivíduo pode construir diferentes composições de capitais culturais, ${ }^{6}$ que podem atuar como agentes de mobilização ou desmobilização em torno de interesses pelas artes.

À escola, por sua vez, caberia a tarefa de compensação das desigualdades de origem no que se refere à formação artística e cultural de públicos menos favorecidos (FLEURY, 2009). No entanto, há que se ressaltar quão problemático tem sido o ensino de artes na educação básica brasileira. Com raras exceções, a educação artística ocupa um lugar periférico nos currículos, cujo ensino quase sempre é focado nas artes plásticas e visuais, em detrimento das demais linguagens.

Hoje, para além da família e da escola formal, outros espaços de socialização precoce merecem atenção para se compreender os processos de formação de jovens artistas, nomeadamente daqueles mais pobres e mais distantes dos contextos tradicionais.

Para alguns dos jovens entrevistados, as experiências espontâneas e quase sempre despretensiosas vividas entre os pares no bairro, na igreja e nas relações de sociabilidade desempenharam um papel-chave na construção de disposições para as artes.

A presença e as formas de uso do espaço público, a oferta de equipamentos de lazer e cultura, a atuação de grupos políticos, religiosos e culturais, bem como a proximidade ou a distância de outras áreas da cidade criam possibilidades diversas de vivenciar o cotidiano e as relações com as artes.

\footnotetext{
${ }^{6} \mathrm{O}$ conceito de capital cultural, embora amplamente conhecido no interior do referencial teórico adotado, merece algumas pequenas notas explicativas. Ele se refere a uma qualificação intelectual e cultural composta por um conjunto de conhecimentos, habilidades e bens culturais adquiridos nos processos de socialização de diferentes grupos e classes sociais (BOURDIEU, 2013).
} 
Nasce-se e vive-se num bairro, embora raramente a vida se desenvolva confinada nos limites desse espaço. Como salienta Alexandre Almeida (2011, p. 2),

\footnotetext{
「...1 o bairro não é abenas uma demarcacão territorial que divide a cidade - servindo para delimitar os esbacos urbanos e o controle administrativo dos servicos búblicos e municibais mas. antes de tudo. o bairro é a próbria constituicão de uma cidade. onde os moradores que nele habitam se identificam, se sociabilizam, criam laços afetivos e sentimentos de pertencimento.
}

Nos bairros populares de Salvador, seus habitantes vivenciam limitações de mobilidade, barreiras simbólicas e materiais (geográficas e financeiras) ao acesso mais democrático a serviços e equipamentos culturais. Como ocorre nas grandes cidades brasileiras, as zonas centrais tendem a concentrar a oferta de instituições culturais e de formação (teatros, museus, galerias, escolas de arte etc.).

Especialmente a partir da adolescência, emerge a possibilidade de ampliação dos deslocamentos do interior do bairro de moradia para outros espaços da cidade, levando à incorporação de um número cada vez maior de referências nas experiências socializadoras e de sociabilidade. Em cidades econômica e espacialmente segregadas como Salvador, o envolvimento com as artes muitas vezes converte-se num veículo fundamental para as experiências de ampliação das relações com os pares e apropriação dos espaços públicos. Dayrell (2002), Ferro (2011) e Caldeira (2012) destacam como jovens de classes populares, quando inseridos em grupos de rap, funk, grafite e parkour, transformam suas relações com a cidade e a cultura, criando novas formas de mobilidade, visibilidade e práticas culturais.

Dentre os entrevistados, Larissa (23, FOT) e Maria (27, VID) são as jovens que vivem nas regiões mais periféricas de Salvador, que distam cerca de 25 quilômetros do Centro da cidade, e sofrem com a escassez de equipamentos e instituições culturais, como ressalta uma delas:

Onde eu moro é muito fraco. Eu fico desesperada porque é fraco demais. E aí eu vejo um monte de menino que deveria estar fazendo alguma coisa, sem nada para fazer, mas lá é muito fraco. (MARIA, 27, VID).

Já Murilo (27, VID) cresceu no Nordeste de Amaralina, bairro popular encravado entre áreas mais "nobres" da cidade. Lá a música era a linguagem artística dominante no cotidiano, e ele e os colegas costumavam se reunir para tocar samba como atividade lúdica e despretensiosa:

Essa arte, o samba, que é uma arte da favela, não era uma opção de vida. Quem tocava era porque gostava de tocar, não existia isso de 'vou fazer música, porque sou músico', isso como uma possibilidade de ganhar a vida. 
O pessoal dizia: 'Não, vou fazer isso e vou trabalhar. Acordar 5 da manhã e vou ser ajudante de obra.' Porque a maioria é assim, até hoje. No bairro, a maioria na minha rua são músicos, bons músicos, tocam muito, mas... (MURILO, 27, VID).

Dentre as diferentes linguagens artísticas, a música é aquela com maior presença no cotidiano e nos rituais das sociabilidades juvenis, sendo mencionada por quase todos os entrevistados. Em diferentes contextos sociais, o interesse e o envolvimento coletivo com determinados gêneros musicais na adolescência e anos iniciais da juventude contribuem para demarcar fronteiras simbólicas, compor códigos de conduta e sistemas de valores, identidades estéticas ou mesmo estilos de vida (GOMES, 2013).

Três jovens viveram no bairro da região da Liberdade, considerada a de maior presença de população negra em Salvador, e marcada pela forte presença de grupos culturais, sendo berço de diversas escolas de samba e de alguns dos principais blocos afros da cidade. Ismael (30, MUS), Diego (29, MUS) e lara (25, DAN) reconhecem o papel do bairro para suas formações artísticas, como sinaliza Diego (29, MUS):

A questão cultural, musical ali é forte. Você vê, a Liberdade tem o bloco llê Aiyê, tem outros grupos culturais e blocos, e diversos movimentos. Tem algumas escolas que têm a questão da fanfarra, que é forte também.

lara (25, DAN) lembra que, por morar no bairro, pôde participar de cursos de dança afro, de desfiles carnavalescos promovidos por blocos afros, como o Muzenza, e ainda formar com as primas um grupo de pagode, ritmo cuja presença é muito intensa na região.

O contato com as mídias também desempenha um papel importante na formação de repertórios e de referências culturais dos jovens, mesmo que ainda seja insuficientemente compreendido do ponto de vista teórico. $\mathrm{O}$ amplo acesso a diversas ferramentas de produção, difusão e consumo das tecnologias da informação e da comunicação tem produzido novos processos de socialização para as gerações mais recentes (SCHWWERTNER; FISCHER, 2012).

Além disso, o trabalho artístico e criativo tem sido objeto de uma crescente mudança e valorização do seu estatuto simbólico. A "mediatização" das profissões (FERREIRA; RAIMUNDO, 2014), por meio de programas de TV (reality shows, concursos etc.) e mídias especializadas que cultuam as celebridades, transformam suas atividades e vidas em objeto de grande visibilidade e reconhecimento social. 
Sidinei (29, DAN), por exemplo, viveu sua infância num período no qual o pagode, produzido por grupos baianos, deixou de ser um fenômeno local e circunscrito a festas populares para atingir projeção radiofônica e televisiva nacional.

Eu digo que o Jacaré, do É o Tchan, foi minha principal referência para dizer: 'Eu gosto de dança! É dança que eu quero!' E aí eu começo a imitá-lo. Então eu levei um bom período da minha vida imitando Jacaré. Ele é um divisor de águas da dança masculina de massa na Bahia. Eu fico feliz, não tenho nenhuma vergonha. Recebo até algumas críticas dentro da Universidade por ter ele como referência. Ele foi uma referência masculina que se tinha: negro, masculino, dançando pagode, com um short relativamente curto, com um jeito de dançar diferenciado.

A força do pagode enquanto referencial cultural também levou lara (27, DAN) a formar seu primeiro grupo de dança, por volta dos 9 anos de idade.

A gente criou um grupo, que nessa época, que era o quê, 96, 97. Todo bairro tinha que ter um grupo de pagode e lá na Liberdade não ia deixar por menos. Tinha um grupo de pagode dos meninos, que era o Tchutchucos... E aí minhas primas começaram a fazer aquela pressão e aí a gente montou um grupo de pagode também, as Tchutchucas... A gentefaziamilhões de eventosnarua.

O grupo perdurou até o início da sua adolescência e, até então, praticamente não acessava os equipamentos culturais disponíveis na cidade, mas tinha amplo contato com o circuito amador de pagode do seu bairro.

Os dois músicos reconhecem a importância da relação mais espontânea com colegas de bairro e com a música popular na construção de repertórios ecléticos, como pontuam:

A gente ouvia de tudo. Então cada semana a gente ouvia uma coisa diferente. Naquela época ainda se alugava DVD na locadora, então em uma semana a gente ouvia Ed Motta, outra semana a gente ouvia Edson Gomes, outra semana a gente ouvia Roupa Nova, outra semana a gente ouvia Oficina G3, que é um expoente muito grande tanto da música gospel. A gente ouvia Charlie Brown Jr. A gente ia e pegava sertanejo, a gente pegava tudo mesmo. (ISMAEL, 30, MUS). 
Algo engraçado que eu costumo falar é que eu não construí nem ídolos. Tem pessoas que curtem Legião Urbana, que têm seus clichês já, e seus movimentos. Eu sempre fui aberto a ouvir de tudo e não me prendi especificamente a nada. Até hoje eu sou assim. Normalmente o instrumentista tem uma direção. O cara que toca acordeão gosta de Dominguinhos e segue. O guitarrista, de Steve Vai, enfim... Eu sempre fui dessa forma, assim, meio plural, e não sei se fiquei meio alheio de alguma forma. Mas por um lado eu acho que estava aberto a tudo. (DIEGO, 29, MUS).

Até os 14 anos de idade, Diego (29, MUS) nunca havia tocado um instrumento e naquele momento crescia nacional e localmente uma cena musical ligada ao forró, em especial a um subgênero denominado "forró universitário", que era dominado por músicos e públicos jovens. Na convivência com amigos do bairro, os desejos de tocar e de constituir um grupo de forró surgiram praticamente no mesmo momento:

Teve a influência também de uma banda que tocava bastante na época, Flor de Milho, e um dos integrantes trabalhava lá na rua, numa locadora em que a gente ia jogar videogame. E aí começou esse contato. Aí ele chamava para ir assistir a banda, acho que era no Estação da Cerveja. Aí a gente ia lá.

Essa imersão no universo da música popular e sua difusão pelas mídias contribuiriam para que construíssem repertórios ecléticos e uma grande aproximação com as culturas populares, sejam elas mais tradicionais ou contemporâneas. Entre eles, nota-se quase sempre um tom de respeito às diferentes manifestações artísticas frequentemente depreciadas por muitos segmentos acadêmicos ou de crítica cultural, como as expressões da dança e da música local (axé, pagode, samba) ou nacional (forró ou funk).

As experiências de socialização religiosa constituíram outro importante espaço de aproximação com o mundo artístico para alguns entrevistados. A família de lara (27, DAN) possui forte ligação com as religiões afro-brasileiras. Sua mãe tem uma relação mais sincrética, como ela mesma define: "Ela tem um altar com Santa Bárbara, com Ogum, Santo Antônio, Oxalá... Tudo junto, misturado", mas seu avô e seu pai exerciam funções sacerdotais no candomblé, sendo respectivamente Ogan e Obá de 
Xangô. ${ }^{7}$ Nessa matriz religiosa, a música e a dança são elementos fundamentais da maior parte dos rituais sagrados e festivos.

Reis (2012), em seu estudo sobre as trajetórias de músicos e dançarinos afro-brasileiros no Brasil e na França, também ressalta o papel que a religiosidade afro-brasileira teve na formação da maioria dos percussionistas entrevistados, pela experiência de socialização musical nos rituais sagrados e festivos dos terreiros de bairros populares de Salvador, que oferecem uma ambiência precoce com ritmos percussivos associados a práticas de expressão corporal.

As instituições religiosas, embora pouco compreendidas enquanto instâncias formadoras de gostos, habilidades e disposições artísticas, têm ocupado um espaço merecedor de destaque nos processos de formação artística contemporânea. Diferentes estudos (BRENNER; DAYRELL; CARRANO, 2005; NOVAES, 2005; SANTOS; MANDARINO, 2005) apontam que atividades religiosas (ir à missa ou aos cultos, participar de grupos culturais ou de catequese etc.) aparecem como uma das principais - quando não a principal - atividade de lazer entre jovens brasileiros nas camadas populares e periféricas.

Larissa (23, FOT) e Ismael (30, MUS), ambos evangélicos, viveram experiências de iniciação artística no interior de igreja. Ela, desde cedo, integrou grupos de dança, teatro e coral na Igreja Batista, e também aprendeu a tocar violão aos treze anos de idade. Ismael pôde participar por mais de quinze anos de grupos e atividades diversas de musicalização e de construção de referências musicais.

Na nossa igreja também, assim, especificamente, iam muitas bandas, e a gente acabava vendo aquelas bandas, e aquela rotatividade de pessoas, aquela musicalidade, então a gente gostava muito disso. (ISMAEL, 30, MUS).

Quando Ismael (30, MUS) iniciou seu curso de graduação em música, já possuía uma longa experiência de formação musical desenvolvida no ambiente religioso, além de ter atuado como instrumentista e cantor com diferentes grupos musicais da cena gospel. Ele pode encontrar, de forma gratuita, professores, instrumentos, espaços para prática e apresentação musical que dificilmente encontraria em outros espaços do bairro onde vivia.

Diferentes vertentes de religiões cristãs católicas e, particularmente, protestantes têm investido maciçamente em expressões artísticas como instrumento de conquista e socialização religiosa de crianças e jovens que, por sua vez, se convertem em agentes centrais na condução da vida cultural das igrejas (JUNGBLUT, 2007).

\footnotetext{
${ }^{7}$ Ogan é a pessoa do sexo masculino que desempenha diferentes funções num terreiro de candomblé, especialmente as de coordenação da ritualística. Obá de Xangô é um título honorífico outorgado a alguns poucos homens, que compõem uma espécie de conselho de amigos e protetores de um terreiro.
} 
A expansão das igrejas evangélicas, particularmente das independentes e neopentecostais, tem-se dado num contexto de crescente inserção nos meios de comunicação de massa (rádio, TV e, mais recentemente, internet), com a consequente midiatização dos cultos e dos artistas gospel (JUNGBLUT, 2007; SANTOS; MANDARINO, 2005). Além disso, tendem a valorizar processos emocionais, catárticos ou místicos que muitas vezes encontram via de expressão em atividades artísticas de música e dança, incorporando novos valores, que permitem uma maior liberação do corpo, dissociando sua expressividade da dimensão sexual.

Desse modo, contra o tradicional ascetismo e afastamento de valores mundanos, entre os cristãos emergem congregações mais plurais e permeáveis a referências estéticas e comportamentais veiculadas globalmente e presentes nas culturas juvenis. A informalidade na linguagem, o gosto pelo rock, reggae ou funk, o culto ao corpo e a prática de esportes radicais não apenas são toleradas, como estimuladas por algumas igrejas (MASCHIO, 2016).

De modo direto ou difuso, diferentes instituições religiosas têm participado dos processos de socialização artística de muitos jovens em Salvador, possibilitando tanto a criação de referências rítmicas e culturais que comunicam sua forte herança sociocultural africana, como processos mais estruturados de iniciação e aprendizagem musical.

\section{PROJETOS SOCIAIS: DA SOCIALIZAÇÃO À PRÉ-PROFISSIONALIZAÇÃO}

Nas últimas três décadas, a experiência de participar de projetos sociais nos bairros periféricos de muitas cidades brasileiras tem desempenhado relevante papel na ampliação de repertórios socioculturais de adolescentes e jovens, através da mediação do acesso às artes e a espaços culturais mais amplos, em concomitância ou não com a experiência escolar (NOVAES, 2006; SPOSITO, 2008). Nos anos 1990, diversas associações, fundações privadas e Organizações Não Governamentais nacionais e internacionais tomaram os jovens como foco de suas ações. Estes sujeitos passaram a ser vistos ora como problemas sociais, ora como parte da solução dos mesmos, em um contexto em que emergia a lógica do protagonismo juvenil, da identificação e formação de lideranças, multiplicadores ou empreendedores sociais (TOMMASI, 2014).

As linguagens artísticas tornaram-se quase um "lugar comum" nas propostas e práticas de projetos sociais voltados para a juventude de classes populares. No entanto, a identificação acrítica entre os termos "juventude", "projeto social" e "arte" muitas vezes contribui para a banalização dessa complexa relação, ora reduzindo a arte a uma função instrumental, ora aproximando-a de lenitivo para os mais diversos problemas que afligem este grupo social.

Em Salvador, no final da década de 1980, a emergência de uma indústria cultural local, calcada sobretudo na música afro-baiana, permitiu a construção de um mercado musical próprio, algo raro na maioria dos estados brasileiros. O carnaval baiano também se consolidou como acontecimento cultural maior em termos de visibilidade nacional e internacional. 
Nesse período, surgiram diversos projetos socioculturais na área de artes, os quais, numa cidade culturalmente rica e socialmente desigual como a capital baiana, encontraram um terreno fértil para sua expansão. Blocos e associações culturais, como o Olodum, o llê Aiyê e o Araketu, e projetos sociais, como o Axé, o Bagunçaço e a Didá, contribuíram para a formação e a profissionalização de uma geração de músicos e dançarinos.

Esse conjunto de instituições e ações constituiu uma rede de formação paralela às instituições de educação formal. Ao menos cinco entrevistados tiveram experiências duradoras e decisivas no interior de projetos sociais, embora o ingresso de cada um tenha ocorrido em diferentes momentos da vida, assim como vivenciaram propostas formativas diversas em termos de concepções pedagógicas, de duração ou mesmo de qualificação dos seus educadores.

A participação em projetos sociais, seja na condição de público-alvo das ações formativas, do engajamento voluntário ou, ainda, como trabalhadores, muitas vezes permite que os jovens construam um status diferenciado nas comunidades onde vivem e nos grupos sociais que integram. Tais vivências geram inputs significativos para os processos de construção de identidades e de habilidades artísticas e políticas, de acesso a novas redes sociais e espaços da cidade, de inserção no debate sobre direitos sociais etc. (SILVA SOBRINHO, 2012).

Maria $(27, V I D)$ é uma das jovens cuja inserção em projetos sociais produziu transformações significativas em sua trajetória. Aos 13 anos começou a fazer aulas de dança numa associação do bairro onde morava. Dois anos depois, ingressou no seu primeiro projeto social, o Agente de Desenvolvimento Comunitário, ligado a uma fundação estadual. Sua proposta era formar jovens mobilizadores e multiplicadores de ações socioculturais com linguagens como poesia, teatro e fotografia, além de sensibilizá-los para temáticas como sexualidade e identidades:

Era um projeto para trabalhar na comunidade. E a partir daí que tudo despertou, que veio meu interesse pela arte, tudo mais. Eu era meio desligada, odiava ler, essas coisas. (MARIA, 27, VID).

Foi por meio do projeto que pôde conhecer alguns circuitos de arte, especialmente os gratuitos ou de baixo custo. Essas experiências possibilitaram mudanças pessoais profundas, no sentido de ressignificar sua relação com seu próprio corpo, sua condição feminina e racial. Segundo ela, essa mudança fica evidente quando reencontra os colegas do bairro com quem viveu a adolescência, que estão casados ou com filhos e trabalhando em atividades menos qualificadas, e ouve falas como: " $D a$ galera, Maria foi a única que tomou um rumo."

Aos 17 anos, Maria (27, VID) pôde expandir ainda mais sua formação artística, dessa vez participando de uma oficina de vídeo ofertada pela Casa Brasil, um projeto localizado num bairro vizinho, aproximando-se mais diretamente da linguagem na qual se formaria alguns anos depois. 
O papel formativo dos projetos sociais também foi decisivo na vida dos três jovens da área de dança, permitindo o acesso a experiências de iniciação artística que são relativamente limitadas para uma parte expressiva da população. Lia (26, DAN) foi a jovem que mais precocemente iniciou suas experiências de formação. Aos 6 anos de idade ingressou em um projeto voltado para a dança, mantido pelo governo estadual.

Naquele momento já realizava pequenas apresentações em espaços públicos. Dois anos depois já estava integrando as atividades de formação do Balé Folclórico Júnior, voltado para as linguagens do balé e da dança afro, por indicação de uma tia, que fora dançarina da instituição.

Aos 15 anos, ingressou em outro projeto, o Balé da Fundação da Criança e do Adolescente (Fundac), que tinha uma proposta mais estruturada de manutenção de um corpo permanente de dançarinos, oferecendo uma bolsa mensal e vale-transporte para os integrantes.

Os três projetos tinham em comum propostas educativas focadas mais diretamente na performance do que em processos de formação cultural e política, o que caracteriza muitas ações socioeducativas voltadas para crianças e adolescentes.

Três anos depois, quando deixou o Balé da Fundac, Lia (26, DAN) já contava com aproximadamente 12 anos de educação e prática em dança, construindo um expressivo capital corporal $^{8}$ em termos de técnicas, algo que normalmente só acontece com públicos das camadas médias ou altas, que podem acessar as escolas particulares de dança e, sobretudo, de balé.

lara (25, DAN), aos 9 anos de idade, começou a participar de uma oficina de dança afro em um centro cultural da Liberdade. O projeto também era mantido pelo governo estadual e oferecia, ainda, atividades de capoeira e teatro. Durante essa experiência, seu professor promoveu sua aproximação com o bloco Muzenza, no qual dançou por três anos no Carnaval. Por volta dos 13 anos, migrou para outro projeto, localizado no Sesc, no qual permaneceu por mais quatro anos, permitindo também uma formação sólida em danças populares.

Sidinei (29, DAN) foi um dos poucos entrevistados a reconhecer que as vivências na educação formal foram importantes para sua formação artística, uma vez que sempre foi propositivo para a realização de atividades culturais de teatro, música e dança nos espaços escolares. Sua primeira aproximação com projetos socioculturais aconteceu no início do ensino fundamental II, com uma participação em oficinas de teatro e dança, no contraturno escolar.

A despeito do pouco espaço ocupado pelas artes nos currículos escolares, muitos colégios públicos brasileiros foram afetados pelo crescimento desse campo de ações dos projetos sociais, realizando parcerias ou incorporando o trabalho de oficineiros e agentes culturais em programas de educação em tempo integral ou em atividades mais pontuais (DAYRELL; GEBER, 2015).

\footnotetext{
${ }^{8}$ Capital corporal se refere a um tipo de capital que inclui a aprendizagem e incorporação de conhecimentos e técnicas corpóreas compreendidas como legitimas em determinado campo, como o de determinados esportes ou áreas da dança (BOURDIEU, 1983).
} 
Foi a partir das experiências com teatro e dança, que possibilitaram um envolvimento intenso com as atividades artísticas, que Sidinei (29, DAN) foi estimulado por um dos educadores a conhecer o Liceu de Artes e Ofícios, onde ingressou por volta dos 15 anos de idade.

$\mathrm{Na}$ instituição, além de receber uma bolsa mensal, pôde contar com uma estrutura mais adequada à prática da dança e ampliar significativamente seu repertório artístico.

As pessoas tinham roupa de dança, tinham tudo isso, e eu cheguei naquele lugar e não sabia. Quando eu entro no Liceu de Artes e Ofícios eu começo a entender alguns princípios das danças populares brasileiras e da dança moderna, especificamente a dança afro-brasileira. (SIDINEI, 29, DAN).

Matriculado apenas no curso de iniciação à dança, também teve acesso a outras oficinas durante os dois anos em que permaneceu no Liceu. Ao sair da instituição, começou a desenvolver voluntariamente oficinas de dança, numa associação do bairro do Engenho Velho da Federação. Na sequência, pôde fazer algumas aulas gratuitas na Escola de Dança da UFBA, com João, um professor que viria a ser uma das suas principais referências.

Aí fiz aula com ele e ele me apresentou e ficou mais do meu lado. Eu digo que ele é o meu pai nesse sentido, porque a partir daquele momento ele começou a introduzir umas questões mais técnicas, começou a propor leituras, questões mais teóricas sobre a dança, do conhecimento de corpo mais amplo... Conhecimento semiótico... que eu não entendia merda de nada naquele momento.(SIDINEI, 29, DAN).

Naquele momento, Sidinei (29, DAN) não apenas experimentara a transformação das suas vivências mais lúdicas e espontâneas com as linguagens artísticas em uma "arte de existência", e desta numa "arte de subsistência" (FERREIRA, 2016). O contato com educadores qualificados e inseridos em círculos mais reconhecidos do mundo da arte contribuiu para a constituição de um capital social ampliado no campo e o acesso às primeiras experiências como profissional da dança.

A partir daí passou a ser colaborador desse educador em oficinas realizadas em uma escola pública. Ambas as experiências como educador eram vistas por Sidinei (29, DAN) também como espaços importantes de aprendizagem e desenvolvimento artístico.

Experiências como as descritas por Maria (27, VID) e pelos três jovens ligados à dança apontam também para outro papel dos projetos sociais, que emergem como contextos de uma "préprofissionalização" no campo artístico. Tais propostas permitem também uma socialização técnica e profissional, na medida em que permitem construir experiências formativas mais estruturadas em 
termos materiais (espaços e equipamentos), da qualificação dos docentes e das referências de atuação profissional em suas respectivas áreas (FERREIRA, 2017), seja na condição de artistas ou de arte-educadores, oficineiros ou educadores sociais (DAYRELL; GEBER, 2015).

Entre os jovens que puderam ter experiências mais prolongadas em projetos sociais, essas iniciativas aparecem como um suporte essencial na construção de habilidades artísticas, que dificilmente seriam possíveis sem elas. Foram decisivas para que pudessem construir redes sociais e um background essencial para ingressarem nos cursos profissionalizantes e superiores.

No caso da dança, o campo de formação para crianças e adolescentes é dominado por escolas privadas, predominantemente focadas no balé clássico, que tendem a atender determinados segmentos populacionais mais privilegiados economicamente. No caso da área de audiovisual e da fotografia, o custo dos equipamentos e a existência de profissionais qualificados nessa linguagem permitiram a Maria (27, VID), a entrevistada que vivia em condições socioeconômicas mais difíceis, experimentar uma ampliação significativa do seu repertório cultural e de perspectivas de futuro.

As experiências em projetos sociais, além de oferecerem oportunidades de ampliação dos capitais culturais dos jovens, proporcionaram condições de formação mais estruturadas, favorecendo também exercícios de pré-formação profissional e da participação social para o jovem.

\section{CONSIDERAÇÕES FINAIS}

Nos processos de socialização artística e profissional investigados, a origem popular comum é apenas uma das múltiplas variáveis (filiação religiosa, instituições escolares frequentadas, local de moradia) que produziram modos plurais - e ao mesmo tempo singulares - de ser artista.

Nem crédulos na ideia de possuírem algum dom inato e genial para as artes, nem herdeiros de capitais socialmente mais valorizados e legitimados das classes economicamente mais privilegiadas, os jovens entrevistados integram uma geração cujos horizontes de possibilidades se alargaram, por via de processos mais alongados de escolarização, mas que nem por isso deixaram de sofrer os constrangimentos de um mundo social marcado pelas desigualdades de acesso ao trabalho, à cultura e à cidade.

As experiências de socialização com as artes nos bairros onde viveram, nas igrejas e nas relações com as mídias, ou em projetos sociais, apontam que os jovens pesquisados têm tecido trajetórias calcadas na "[...] construção de uma estética emancipatória, voltada para a auto-realização e auto-afirmação do sujeito, bem como para a busca de uma ética pessoal, na base de um exercício de liberdade individual, e não para obediência de um código de regras colectivas", como pontua Ferreira (2010, p. 118), na perspectiva de Foucault. Questionaram caminhos mais normativos e esperados para os segmentos socioeconômicos de onde vieram. Se por um lado não desacreditam do valor simbólico dos diplomas - todos chegaram ao ensino superior -, permitem-se conquistá-los em terrenos menos óbvios e esperados para pessoas oriundas das camadas populares. 
A extensão das trajetórias de formação contraria ideias comuns que associam o artista ao autodidatismo ou o veem como um dissidente escolar. Além disso, sugerem que mesmo diante de um contexto social que projeta horizontes profissionais nebulosos para a juventude, não deixam de desejar e trabalhar para converter sonhos em projetos profissionais ou em artes de subsistência.

Os diferentes modos de existir e sobreviver no campo artístico não são meras respostas reflexas aos constrangimentos impostos pelo mundo do trabalho; estes jovens de origem popular também constituem modos de atuar produtivos e criativos, e não apenas reativos, contribuindo para criar e formar públicos, espaços e redes, e afirmar a existência de um novo estatuto do artista, menos elitizado e construído no "aprender fazendo" cotidiano, a partir de processos plurais de socialização. Como diria Basbaum (2014, p. 32-33), o artista "produz obras de arte, sim, mas produz muito mais: produz também um lugar de produção, o lugar do artista".

\section{REFERÊNCIAS}

ALMEIDA, A. P. Uma análise sobre sociabilidade, cotidiano e vizinhança em um bairro popular de João Pessoa-PB. Ponto Urbe, n. 9, p. 1-12, 2011. Disponível em: <http://pontourbe.revues.org/287>. Acessoem: 10 jul. 2016. DOI : 10.4000/pontourbe.287.

2. ALMEIDA, M. I. M. Criatividade contemporânea e os redesenhos das relações entre autor e obra: a exaustão do rompante criador. In: ALMEIDA, M. I. M.; PAIS, J. M. (Org.). Criatividade, juventude e novos horizontes profissionais. Rio de Janeiro: Zahar, 2012. p. 21-55.

3. $\quad$ BASBAUM, R. Mediações. In: FERNANDES, M. Q. (Org.). Longitudes: a formação do artista contemporâneo no Brasil. São Paulo: Casa do Povo, 2014. p. 24-33.

4. BECKER, H. Mundos artísticos e tipos sociais. In: VELHO, G. (Org.). Arte e sociedade: ensaios de sociologia da arte. Rio de Janeiro: Zahar, 1977. p. 9-26.

5. BOURDIEU, P. As regras da arte: gênese e estrutura do campo literário. São Paulo: Companhia das Letras, 1996.

6. Capital simbólico e classes sociais. Novos estudos - CEBRAP, São Paulo, n. 96, p. 105-115, jul. 2013.

Questões de sociologia. Rio de Janeiro: Marco Zero, 1983. 
BRENER, A. K.; DAYRELL, J.; CARRANO, P. C. Culturas do lazer e do tempo livre dos jovens brasileiros. In: ABRAMO, H., BRANCO, L. H. (Org.). Retratos da juventude brasileira: análise de uma pesquisa nacional. São Paulo: InstitutoCidadania/FundaçãoPerseuAbramo, 2005. p. 175-242.

CALDEIRA, T. P. Inscrição e circulação: novas visibilidades e configurações do espaço público em São Paulo. Novosestududos - CEBRAP, São Paulo, n. 94, p. 31-67, 2012.

DAYRELL, J. O rap e o funk na socialização da juventude. Educação e Pesquisa, São Paulo, v. 28, n. 1, p. 117-136, jun. 2002.

DAYRELL, J.; GEBER, S. Os "novos" educadores dos programas de educação integral: uma análise das práticas educativas dos agentes culturais. EducaçãoemRevista, v. 31, n. 4, p. 45-62, out./dez. 2015.

FARIA, Ivan. Viver de arte: percursos de formação e inserção socioprofissional de egressos de cursos de educação profissionalizante em artes, em Salvador, Bahia. 2017. 292f. Tese (Doutorado em Educação) - Universidade Federal de Minas Gerais, Belo Horizonte, 2017.

FERREIRA, V. S. Cenas juvenis, políticas de resistência e artes de existência. Trajectos, n. 16, p. 111-119, 2010. Aesthetics of youth scenes: from arts of resistance to arts of existence. Young, v. 1, n. 24, p. 66-81, 2016. Disponível em: <http://journals.sagepub.com/doi/abs/10.1177/1103308815595520>. Acesso em: 15 jan 2017. DOI: 10.1177/1103308815595520 Ser DJ não é só soltar o play: a pedagogização de uma nova profissão de sonho. Revista Educação \& Realidade, v. 42, n. 2, p. 473-494, 2017. Disponível em: <http://www.scielo.br/pdf/edreal/v42n2/2175-6236-edreal-42-02-00473.pdf>. Acesso em 15 jan 2018. DOI: 10.1590/2175-623664318 sentido em novas profissões de sonho entre jovens. In: CONGRESSO PORTUGUÊS DE 
SOCIOLOGIA, 40 anos de democracia(s): progressos, contradições e prospectivas, 8., 2014, Évora.

Actas... Évora: Universidade de Évora, 2014. p. 1-10.

FERRO, L. S. A. P. Da rua para o mundo: configurações do graffiti e do parkour e campos de possibilidades urbanas. 2011. $271 \mathrm{f}$. Tese (Doutorado em Sociologia) - Instituto Universitário de Lisboa (ISCTE), Lisboa, 2011. Disponível em: <http://hdl.handle.net/10071/4223>. Acesso em: 07 fev. 2018.

FLEURY, L. Sociologia da cultura e das práticas culturais. São Paulo: Senac, 2009.

GOMES, R. T. Fazer música underground: estetização do quotidiano, circuitos juvenis e ritual. 2013. 271 f. Tese (Doutorado em Sociologia) - Instituto Universitário de Lisboa (ISCTE), Lisboa, 2013.

INFOCULTURA: ocupação e trabalho na economia criativa do estado da Bahia. Salvador: Secretaria de Cultura do Estado da Bahia, v. 1, n. 7, dez. 2014.

21. JUNGBLUT, A. L. A salvação pelo Rock: sobre a "cena underground" dos jovens evangélicos no Brasil. Religião e Sociedade, v. 27, n. 2, p. 144-162, dez. 2007. Disponível em: <http://www.scielo.br/scielo.php?script=sci_arttext\&pid=S0100-85872007000200007>. Acesso em: 16 ago. 2011.

LAWRENCE, T.; PHILLIPS, N. Compreendendo as indústrias culturais. In: KIRSCHBAUM, C. Et al (Org.). Indústrias criativas no Brasil. São Paulo: Atlas, 2009. p. 3-23.

MASCHIO, M. Juventude e religião evangélica: a cultura como missão na Comunidade Gólgota e na Bola de Neve Church. In: SIMPÓSIO INTERNACIONAL DA ABHR, 6., 2016, Florianópolis. Anais... Florianópolis: UFSC, 2016.

NOVAES, R. Juventude, percepções e comportamentos: a religião faz a diferença. In: ABRAMO, H; BRANCO, P. P. (Org.). Retratos da juventude brasileira: análises de uma pesquisa nacional. São Paulo: FundaçãoPerseuAbramo, 2005. p. 263-290. 

Os jovens de hoje: contextos, diferenças e trajetórias. In: ALMEIDA, M. I. M.; EUGENIO, F. (Org.). Culturas jovens: novos mapas do afeto. Rio de Janeiro: Zahar, 2006. p. 105-120.

REIS, C. F. Sonhos, incertezas e realizações: as trajetórias de músicos e dançarinos afro-brasileiros no Brasil e na França. 2012. 290 f. Tese (Doutorado em Ciências Sociais) - Universidade Estadual de Campinas, Campinas, SP, 2012.

SANTOS, E. S.; MANDARINO, C. M. Juventude e religião: cenários no âmbito do lazer. Revista de Estudos da Religião, n. 3, p. 161-177, 2005. Disponível em:

$<w w w . p u c s p . b r / r e v e r / r v 3 \_2005 / p \_s a n t o s . p d f>$. Acesso em: 08 fev. 2018.

SCHWWERTNER, S.; FISCHER, R. Juventudes, conectividades múltiplas e novas temporalidades. EducaçãoemRevista, v. 28, n. 1, p. 395-420, mar. 2012.

SHAPIRO, R.; HEINICH, N. Quando há artificação? Sociedade e Estado, v. 28, n. 1, p. 1428, abr. 2013. Disponível em: <http://www.scielo.br/pdf/se/v22n1/v22n1a06.pdf>. Acesso em: 27 dez. 2017.

SILVA SOBRINHO, A. L. "Jovens de projetos" nas ONGs: olhares e vivências entre o engajamento político e o trabalho no "social". 2012. 114 f. Dissertação (Mestrado em Educação) - Universidade Federal Fluminense, Niterói, RJ, 2012. SPOSITO, M. P. Juventude e educação: interações entre educação escolar e a educação nãoformal. Educação\&Realidade, v. 33, n. 2, p. 83-97, 2008.

32. TOMMASI, L. Tubarões e peixinhos: histórias de jovens protagonistas. Educação e Pesquisa, v. 40, p. 533-548, 2014. 
Ivan Faria:

Possui Bacharelado em Psicologia pela Universidade Federal da Bahia (1999), Mestrado em Educação pela UFBA (2006) e Doutorado em Educação pela UFMG (2017). Professor do Departamento de Educação da Universidade Estadual de Feira de Santana (UEFS) e membro dos grupos de pesquisa Observatório da Juventude/UFMG e TRACE/UEFS. Desenvolve pesquisa sobre juventude, cultura, arte, educação, educação-trabalho, formação artística.

\section{Vitor Sérgio Ferreira:}

Doutor em Sociologia pelo Instituto Universitário de Lisboa (ISCTE). Investigador Auxiliar do Instituto de Ciências Sociais da Universidade de Lisboa. Coordenador do LIFE - Research Group.

\section{Juarez Tarcísio Dayrel:}

Doutor em Educação pela Universidade de São Paulo (USP). Professor Associado da Universidade Federal de Minas Gerais (UFMG). Membro do Observatório da Juventude da Universidade Federal de Minas Gerais (OJ/UFMG).

\section{Como citar este documento:}

FARIA, Ivan. A ARTE COMO ARTE DE EXISTÊNCIA: EXPERIÊNCIAS DE SOCIALIZAÇÃO DE JOVENS DE ORIGEM POPULAR EM SALVADOR, BAHIA. Reflexão e Ação, Santa Cruz do Sul, v. 26, n. 2, $2018 . \quad$ ISSN 1982-9949. Disponível em: <https://online.unisc.br/seer/index.php/reflex/article/view/11717>. Acesso em: __. doi: http://dx.doi.org/10.17058/rea.v26i2.11717. 